\title{
Radiation recall pneumonitis induced by chemotherapy after thoracic radiotherapy for lung cancer
}

Xiao Ding ${ }^{1+}$, Wei $\mathrm{Ji}^{1,3+}$, Junling $\mathrm{Li}^{2}$, Xiangru Zhang ${ }^{2}$, Luhua Wang ${ }^{1 *}$

\begin{abstract}
Background: Radiation recall pneumonitis (RRP) describes a rare reaction in previously irradiated area of pulmonary tissue after application of triggering agents. RRP remains loosely characterized and poorly understood since it has so far only been depicted in 8 cases in the literature. The objective of the study is to disclose the general characteristics of RRP induced by chemotherapy after thoracic irradiation for lung cancer, and to draw attention to the potential toxicity even after a long time interval from the previous irradiation.

Methods: Medical records were reviewed. RRP induced by chemotherapy was diagnosed by the history of chemotherapy after radiotherapy, clinical presentation and radiographic abnormalities including ground-glass opacity, attenuation, or consolidation changes within the radiation field, plus that radiographic examination of the thorax before showed no radiation pneumonitis. RRP was graded according to Common Terminology Criteria for Adverse Events version 3.0. The characteristics of the 12 RRP cases were analyzed.

Results: Twelve patients were diagnosed of RRP, of who 8 received taxanes. The median time interval between end of radiotherapy and RRP, between end of radiotherapy and beginning of chemotherapy, and between beginning of chemotherapy and RRP was 95 days, 42 days and 47 days, respectively. Marked symptomatic and radiographic improvement was observed in the 12 patients after withdrawal of chemotherapy and application of systemic corticosteroids. Seven patients were rechallenged with chemotherapy, of whom four with the same kind of agents, and showed no recurrence with steroid cover.
\end{abstract}

Conclusions: Doctors should pay attention to RRP even after a long time from the previous radiotherapy or after several cycles of consolidation chemotherapy. Taxanes are likely to be associated with radiation recall more frequently. Withdrawal of causative agent and application of steroids are the treatment of choice. Patients may be rechallenged safely with steroid cover and careful observation, which needs to be validated.

\section{Background}

Radiation recall reaction (RRR) refers to an inflammatory reaction within the previously treated radiation field in response to precipitating agents, which could have been masked if radiotherapy is not followed by inciting agents. It has been observed mainly with chemotherapeutic drugs [1]. Nevertheless, antituberculosis drugs, antibiotics, tamoxifen, simvastatin have also

\footnotetext{
* Correspondence: whlhwq@yahoo.com

+ Contributed equally

'Department of Radiation Oncology, Cancer Institute (Hospital), Chinese Academy of Medical Sciences and Peking Union Medical College, Beijing, PR China

Full list of author information is available at the end of the article
}

been involved in it [2-6]. Skin is the major site of radiation recall toxicity [7]. But it has been as well described in different internal organs including lung, digestive tract, muscle, central nervous system, and supraglottis [8-16]. Treatment-related pneumonitis is a major doselimiting toxicities resulting from thoracic radiotherapy and chemotherapy. Radiation recall pneumonitis (RRP) describes a rare reaction in previously irradiated area of pulmonary tissue after application of triggering agents. The diagnosis of RRP induced by chemotherapy is established by a history of chemotherapy after thoracic radiotherapy, radiographic abnormality, and clinical presentation. The typical radiologic changes of RRP include ground-glass opacity, diffuse haziness, infiltrates or

\section{Biomed Central}


consolidation in the irradiated lung that conform to the shape and size of the treatment portals [17]. The symptoms are dry cough, low-grade fever, chest pain, and shortness of breath. The antineoplastic agents having been reported to trigger RRP include taxanes, anthracyclines, gemcitabine and erlotinib [8,18-23].

RRP remains loosely characterized and poorly understood since it has so far only been depicted in 8 cases $[8,18-23]$ in the literature. The objective of the present study is to disclose the general characteristics of RRP induced by chemotherapy after thoracic irradiation of lung cancer, and to draw attention to the potential toxicity even after a long time interval from the previous irradiation.

\section{Methods}

We retrospectively reviewed the medical and radiation records of lung cancer patients who were treated consecutively between January 1999 and December 2007 in the Department of Radiation Oncology at Cancer Hospital, Chinese Academy of Medical Sciences, Peking Union Medical College. Patients were included if they had newly diagnosed and pathologically confirmed lung cancer, chemotherapy after thoracic radiotherapy, a lung dose-volume histogram (DVH) that was recoverable from institutional archives, and availability of both radiographic images and symptom assessment for determining the occurrence of RRP.

The total normal lung volume was defined as the total lung volume minus the primary gross target volume (GTV) and volume of the trachea and main bronchi. The following dosimetric parameters were generated from the DVH for total normal lung: mean lung dose (MLD), and lung volumes receiving more than $5 \mathrm{~Gy}$ (V5), 10 Gy (V10), 20 Gy (V20), and 30 Gy (V30).

All patients were examined by their treating radiation oncologists weekly during radiotherapy and 4-6 weeks after completion of radiotherapy. The patients were then followed every 3 months for the first 3 years and every 6 months thereafter unless they had symptoms that required immediate examination or intervention. Radiographic examination by chest X-ray or CT was performed at each follow-up visit after completion of radiotherapy.

RRP induced by chemotherapy was diagnosed by the history of chemotherapy after radiotherapy, clinical presentation and radiographic abnormalities including ground-glass opacity, attenuation, or consolidation changes within the radiation field, plus that radiographic examination of the thorax before showed no radiation pneumonitis. RRP was graded according to the National Cancer Institute's Common Terminology Criteria for Adverse Events (CTC) version 3.0 (23) as follows: Grade 1 pneumonitis was asymptomatic and diagnosed by radiographic findings only; Grade 2 pneumonitis was symptomatic but did not interfere with daily activities; Grade 3 pneumonitis was symptomatic and interfered with daily activities or required administration of oxygen to the patient; Grade 4 pneumonitis required assisted ventilation for the patient; and Grade 5 pneumonitis was fatal. Informed consent was obtained from all the subjects.

\section{Results}

Twelve patients were diagnosed of RRP induced by consolidation chemotherapy. The median age of the group was 51 years (range, 41-66 years). 5 patients were female, and 7 male. Three cases are limited small cell lung cancer (SCLC), and 9 are locally-advanced non small cell lung cancer (NSCLC). All patients' Karnofsky performance status (KPS) was 80. Five patients had induction chemotherapy, and 7 had concurrent chemotherapy. The 12 lung cancer patients' clinical characteristics are shown in Table 1.

Eight patients received 3-dimentional conformal radiotherapy (3D-CRT), and 4 received intensitymodulated radiotherapy (IMRT). The median radiation dose was 60.7 Gy (range, 52-66 Gy). The median MLD was 1540.5 cGy (range, 1301-2130 cGy). The median V5, V10, V20 and V30 was 53.3\% (range, 38.0\%65.0\%), 41.0\% (range, 29.0\%-51.0\%), 26.9\% (range, 20.0\%-32.0\%), and 20.2\% (range, 15.0\%-27.0\%), respectively. The 12 lung cancer patients' dosimetric parameters are shown in Table 2.

Of the 12 intravenous consolidation chemotherapy regimens inducing RRP, 8 included taxanes, 2 of which included both taxanes and gemcitabine; 2 etoposide; 1 vinorelbine; and 1 epirubicin.

The median time interval between end of radiotherapy and RRP, between end of radiotherapy and beginning of chemotherapy, and between beginning of chemotherapy and RRP was 95 days (range, 71-202 days), 42 days (range, 7-60 days) and 47 days (range, 22-169 days), respectively.

Eleven patients had Grade 2 and 1 patient had Grade 3 RRP. Marked symptomatic and radiographic improvement was observed in the 12 patients after withdrawal of the chemotherapy and application of systemic corticosteroids. Of the 12 RRP patients, 7 were rechallenged with chemotherapy, 3 of who were rechallenged with the same agents and 1 with the same kind of agents, and showed no recurrence with steroid cover. The median time interval between RRP and rechallenge was 20 days (range, 4-89 days). The characteristics of the 12 RRP cases are shown in Table 3.

Figure 1 shows the thoracic CT scans of Patient 10 (A) before radiotherapy, (B) one month after end of radiotherapy, (C) 4 months after end of radiotherapy when 
Table 1 Clinical characteristics of the 12 lung cancer patients

\begin{tabular}{|c|c|c|c|c|c|c|c|}
\hline Patient & Sex & Age & Histology & Stage $^{a}$ & KPS & Induction chemotherapy & Concurrent chemotherapy \\
\hline 1 & $\mathrm{~F}$ & 51 & small cell lung cancer & $\begin{array}{c}\text { Illa } \\
\text { T1N2M0 }\end{array}$ & 80 & CE & No \\
\hline 2 & $\mathrm{~F}$ & 50 & Adenocarcinoma & $\begin{array}{c}l l l b \\
\text { T2N3M0 }\end{array}$ & 80 & No & PC \\
\hline 3 & M & 54 & Squamous cell carcinoma & $\begin{array}{c}\text { Illa } \\
\text { T3N2M0 }\end{array}$ & 80 & No & EP \\
\hline 4 & M & 48 & small cell lung cancer & $\begin{array}{c}\text { Illa } \\
\text { T2N2M0 }\end{array}$ & 80 & CE & No \\
\hline 5 & F & 59 & Adenocarcinoma & $\begin{array}{c}\text { IIIb } \\
\text { T3N3M0 }\end{array}$ & 80 & NP & No \\
\hline 6 & M & 49 & Squamous cell carcinoma & $\begin{array}{c}\text { Illa } \\
\text { T3N2M0 }\end{array}$ & 80 & PC & EP \\
\hline 7 & M & 58 & Squamous cell carcinoma & $\begin{array}{c}\text { Illa } \\
\text { T2N2MO }\end{array}$ & 80 & No & EP \\
\hline 8 & $\mathrm{~F}$ & 63 & Adenocarcinoma & $\begin{array}{c}\text { IIla } \\
\text { T2N2MO }\end{array}$ & 80 & No & PC \\
\hline 9 & M & 44 & Squamous cell carcinoma & $\begin{array}{c}\text { IIIb } \\
\text { T4NOMO }\end{array}$ & 80 & No & PC \\
\hline 10 & $\mathrm{~F}$ & 41 & Adenocarcinoma & $\begin{array}{c}I \| b \\
\text { T4N2M0 }\end{array}$ & 80 & No & EP \\
\hline 11 & M & 46 & small cell lung cancer & $\begin{array}{c}\text { Illa } \\
\text { T2N2M0 }\end{array}$ & 80 & EP & No \\
\hline 12 & M & 66 & Squamous cell carcinoma & $\begin{array}{c}\text { Illa } \\
\text { T2N2M0 }\end{array}$ & 80 & No & No \\
\hline
\end{tabular}

KPS indicates Karnofsky performance status; CE, carboplatin, etoposide; NP, navelbine, cisplatin; PC, Paclitaxel, carboplatin; EP, etoposide, cisplatin.

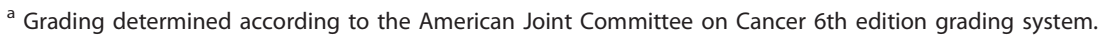

RRP took place induced by consolidation chemotherapy, and (D) days after application of systematic steroids, suggestive of RRP development. Figure 2 shows CT based IMRT plan of Patient 10.

\section{Discussion}

RRR describes an inflammatory reaction in previously irradiated area after application of certain promoting agents. When it occurs in previously irradiated lung, it is called RRP. RRP is a special subtype of radiation induced pneumonitis, as the base of RRP is subclinical radiation damage of pulmonary tissue. When radiation therapy is followed by chemotherapy, subclinical damage from irradiation can be unmasked and clinically manifested as a radiation recall phenomenon.

Taxanes and anthracyclines have been reported to be responsible for $20 \%$ and nearly $30 \%$ of RRR, respectively [1]. The inciting agents observed in RRP previously reported and here included taxanes, anthracyclines, gemcitabine, etoposide, vinorelbine and erlotinib. Taxanes and anthracyclines are responsible for the majority of the 20 chemotherapy-induced RRP cases available, $50 \%$ and $25 \%$ respectively. In the present study, of the 12 regimens, 8 (66.7\%) included taxanes, $2(16.7 \%)$ of which included both taxanes and gemcitabine; 2 (16.7\%) etoposide; 1 vinorelbine; and 1 epirubicin. Certain drugs seem to be associated with radiation recall more frequently. On the other hand, cisplatin and carboplatin, which are frequently used after radiotherapy, has not been depicted in RRR. In contrast, radiation recall induced by oxaliplatin has been reported [24]. When a combination of gemcitabine and docetaxel was involved, we assume that RRP was induced by the combination, as it could not completely be ruled out that the pulmonary recall reaction was not caused by either, although the time intervals from the last application of the two agents to the RRP were different.

So far, we are the first to describe etoposide-induced RRP with details. Moreover, we are the first to describe RRR by Vinorelbine beyond one suspected RRR case after a first cycle of gemcitabine and Vinorelbine with no details [22].

Classic RRR often occurs with the initiation of the precipitating agent but can occur after several courses of treatment. The time delay of cases that occurred after several courses of treatment could be explained by a putative drug dose threshold for RRP or/and a time lag effect. Clinically, these patients' symptoms were considered to be triggered by chemotherapy. Both radiotherapy and chemotherapy contributed to the development of RRP, and it is difficult to tell how much each of them contributed in each case. The reported time interval between the end of radiation therapy and the recall reaction ranged from 2 days [25] to 15 years [26]. 
Table 2 Dosimetric parameters of the 12 lung cancer patients

\begin{tabular}{|c|c|c|c|c|c|c|}
\hline Patient & Radiotherapy & $\begin{array}{l}\text { MLD } \\
\text { (cGy) }\end{array}$ & $\begin{array}{l}\text { V5 } \\
\text { (\%) }\end{array}$ & $\begin{array}{l}\text { V10 } \\
\text { (\%) }\end{array}$ & $\begin{array}{l}\text { V20 } \\
\text { (\%) }\end{array}$ & $\begin{array}{l}\text { V30 } \\
\text { (\%) }\end{array}$ \\
\hline 1 & $\begin{array}{c}\text { 3D-CRT } \\
60 G y / 30 F / 41 D\end{array}$ & 1560 & 46.0 & 41.0 & 26.5 & 22.0 \\
\hline 2 & $\begin{array}{c}\text { IMRT } \\
54 \mathrm{~Gy} / 24 \mathrm{~F} / 37 \mathrm{D}\end{array}$ & 1489 & 63.0 & 47.0 & 27.0 & 19.0 \\
\hline 3 & $\begin{array}{c}\text { 3D-CRT } \\
62.6 \mathrm{~Gy} / 34 \mathrm{~F} / \\
36 \mathrm{D}\end{array}$ & 1591 & 49.0 & 40.0 & 29.0 & 22.0 \\
\hline 4 & $\begin{array}{c}\text { IMRT } \\
\text { 60Gy/30F/39D }\end{array}$ & 1319 & 55.0 & 38.0 & 24.0 & 15.0 \\
\hline 5 & $\begin{array}{c}\text { 3D-CRT } \\
52 \mathrm{~Gy} / 26 \mathrm{~F} / 36 \mathrm{D}\end{array}$ & 1819 & 65.0 & 51.0 & 32.0 & 27.0 \\
\hline 6 & $\begin{array}{c}\text { 3D-CRT } \\
63 G y / 35 F / 56 D\end{array}$ & 2130 & 62.0 & 44.0 & 28.0 & 21.0 \\
\hline 7 & $\begin{array}{c}\text { 3D-CRT } \\
61.4 \mathrm{~Gy} / 34 \mathrm{~F} / \\
48 \mathrm{D}\end{array}$ & 1301 & 42.0 & 30.0 & 20.0 & 17.0 \\
\hline 8 & $\begin{array}{c}\text { 3D-CRT } \\
63 \mathrm{~Gy} / 35 \mathrm{~F} / 52 \mathrm{D}\end{array}$ & 1521 & 39.9 & 33.5 & 24.7 & 20.5 \\
\hline 9 & $\begin{array}{c}\text { 3D-CRT } \\
64.6 \mathrm{~Gy} / 35 \mathrm{~F} / \\
53 \mathrm{D}\end{array}$ & 1755 & 38.0 & 29.0 & 22.0 & 19.0 \\
\hline 10 & $\begin{array}{c}\text { IMRT } \\
66 \mathrm{~Gy} / 33 \mathrm{~F} / 45 \mathrm{D}\end{array}$ & 1667 & 57.2 & 40.9 & 27.8 & 19.9 \\
\hline 11 & $\begin{array}{c}\text { IMRT } \\
60 \mathrm{~Gy} / 30 \mathrm{~F} / 38 \mathrm{D}\end{array}$ & 1444 & 54.5 & 43.7 & 26.8 & 19.0 \\
\hline 12 & $\begin{array}{c}\text { 3D-CRT } \\
56 \mathrm{~Gy} / 28 \mathrm{~F} / 38 \mathrm{D}\end{array}$ & 1445 & 52.0 & 46.0 & 28.0 & 22.0 \\
\hline
\end{tabular}

MLD indicates mean lung dose; 3D-CRT, 3-dimensional conformal radiotherapy; IMRT, intensity-modulated radiotherapy.

The reported time interval between the first dose of chemotherapy and the recall reaction ranged from 18 hours [27] to 15 years [26]. In the literature, the time interval between completion of radiotherapy and RRP ranged from 12 days [8] to 9 months [21], the time interval between completion of radiotherapy and beginning of chemotherapy ranged from 12 days [8] to 8 months [21], and the time interval between beginning of chemotherapy and RRP ranged from several hours [8] to 2 months [19]. In the present study, the median time interval between end of radiotherapy and RRP, between end of radiotherapy and beginning of chemotherapy, and between beginning of chemotherapy and RRP was 95 days (range, 71-202 days), 42 days (range, 7-60 days) and 47 days (range, 22-169 days), respectively. RRP could occur even after a long time interval from the previous radiotherapy or after several cycles of consolidation chemotherapy. Because we generally recommend our patients have consolidation chemotherapy 4-8 weeks after radiotherapy in our institute if the patients are evaluated able to take chemotherapy. The time interval from the end of radiotherapy to RRP here could not be very long.
Previous published articles have reported that recall reactions are most severe when the time interval between the radiotherapy and the following chemotherapy is short. We did not find the trend in our study, the reason for that may be there are other factors, such as primary disease, patient's performance status, radiotherapy and inciting agents. Referring to all the chemotherapy-induced RRP cases reported and here, the median time interval from completion of radiotherapy to beginning of chemotherapy was 34 days (range, 12-59 days) for taxanes, 6 weeks (range, 3-8 weeks) for anthracyclines, 59 days (range, 56 days- 8 months) for combination of gemcitabine and docetaxel; the median time interval from beginning of chemotherapy and RRP was 51 days (range, 36 hours-169 days) for taxanes, 12 hours (range, several hours-2 months) for anthracyclines, 30 days (range, 22-38 days) for combination of gemcitabine and docetaxel; and the median time interval from completion of radiotherapy and RRP was 95 days (range, 12-202 days) for taxanes, 6 weeks (range, 3 weeks-4 months) for anthracyclines, 94 days (range, 81 days-9 months) for combination of gemcitabine and docetaxel. Probably, the time interval plays a crucial role in the pathophysiological mechanism.

Standard treatment for radiation recall includes withdrawal of the precipitating agent, application of corticosteroids and supportive care. Marked symptomatic and radiographic improvement has been observed in all the 12 patients after withdrawal of the chemotherapy and application of systemic corticosteroids. The most confusing aspect in the treatment of RRP is to decide whether to give up the inciting drug even chemotherapy or not. This must be considered since it means that an effective treatment of a patient's malignancy stops. Of our 12 RRP patients, 7 were rechallenged with chemotherapy, of which 3 were rechallenged with the same agents and 1 with the same kind of agents, and showed no recurrence with steroid cover. In the literature 2 RRP patients rechallenged with adriamycin [19] and paclitaxel [8] respectively showed no recurrence with steroid cover. As for radiation recall dermatitis (RRD) that has relatively more evidence of rechallenge in the literature, drug rechallenge tends to produce either only a mild recurrence or no recurrence of recall [7]. Hence, it may work to rechallenge RRP patient with the same agent with steroid cover and careful observation, which needs more data to verify. However, it should be noted that our 12 patients whose KPS was 80 received 3D-CRT or IMRT. Furthermore, with steroid cover, we only rechallengd the patients whom we clinically assessed could take it. Also, it is possible that the rechallenged patients may have showed recurrence without steroid cover or selection. 
Table 3 Characteristics of the 12 RRP cases

\begin{tabular}{|c|c|c|c|c|c|c|c|c|c|c|}
\hline Patient & $\begin{array}{l}\text { Consolidation } \\
\text { chemotherapy }\end{array}$ & $\begin{array}{l}\text { Time interval } \\
\text { between end } \\
\text { of RT and } \\
\text { RRP (days) }\end{array}$ & $\begin{array}{l}\text { Time interval } \\
\text { between end of } \\
\mathrm{RT} \text { and } \\
\text { beginning of } \\
\text { ChT (days) }\end{array}$ & $\begin{array}{l}\text { Time interval } \\
\text { between } \\
\text { beginning of } \\
\text { ChT and RRP } \\
\text { (days) }\end{array}$ & Fever & $\begin{array}{l}\text { Cough } \\
\text { Grade }\end{array}$ & $\begin{array}{l}\text { Grade of } \\
\text { shortness } \\
\text { of breath }\end{array}$ & $\begin{array}{l}\text { RRP } \\
\text { Grade }\end{array}$ & Rechallenge & $\begin{array}{c}\text { Time interval } \\
\text { between RRP } \\
\text { and } \\
\text { rechallenge } \\
\text { (days) }\end{array}$ \\
\hline 1 & CEV $\times 2$ & 71 & 42 & 29 & $<38^{\circ} \mathrm{C}$ & 2 & 2 & 2 & No & \\
\hline 2 & $D \times 1$ & 82 & 31 & 51 & $<38^{\circ} \mathrm{C}$ & 3 & 0 & 3 & No & \\
\hline 3 & $\mathrm{GD} \times 1$ & 81 & 59 & 22 & $<38^{\circ} \mathrm{C}$ & 0 & 0 & 2 & $\mathrm{GD}$ & 14 \\
\hline 4 & CEX4 & 94 & 15 & 79 & No & 2 & 0 & 2 & $P$ & 89 \\
\hline 5 & $N P \times 2$ & 102 & 60 & 42 & $<38^{\circ} \mathrm{C}$ & 0 & 2 & 2 & No & \\
\hline 6 & $P C \times 2$ & 86 & 46 & 40 & $\begin{array}{c}<38.5^{\circ} \\
C\end{array}$ & 2 & 2 & 2 & D & 85 \\
\hline 7 & $\mathrm{GD} \times 2$ & 94 & 56 & 38 & $<38^{\circ} \mathrm{C}$ & 0 & 0 & 2 & GD & 20 \\
\hline 8 & $P C \times 1$ & 95 & 59 & 36 & $<38^{\circ} \mathrm{C}$ & 2 & 0 & 2 & PC & 20 \\
\hline 9 & $\mathrm{PC} \times 2$ & 105 & 34 & 71 & No & 2 & 2 & 2 & NP & 73 \\
\hline 10 & $P C \times 2$ & 118 & 41 & 77 & $<38^{\circ} \mathrm{C}$ & 1 & 2 & 2 & No & \\
\hline 11 & $E P \times 4$ & 171 & 7 & 164 & No & 2 & 0 & 2 & $\mathrm{Gl}$ & 4 \\
\hline 12 & $\mathrm{PC} \times 3$ & 202 & 31 & 169 & $<38^{\circ} \mathrm{C}$ & 2 & 0 & 2 & No & \\
\hline
\end{tabular}

RRP indicates radiation recall pneumonitis; CEV, cyclophosphamide, epirubicin, vincristine; D, docetaxel; GD, gemcitabine, docetaxel; CE, carboplatin, etoposide; $\mathrm{NP}$, navelbine, cisplatin; PC, paclitaxel, carboplatin; EP, etoposide, cisplatin; RT, radiotherapy; ChT, chemotherapy; $\mathrm{P}$, paclitaxel; Gl, gemcitabine, ifosfamide.

The etiology and pathogenesis of RRR are not completely understood. One hypothesis is that local vascular permeability or proliferative changes induced by radiotherapy might affect the subsequent pharmacokinetics of the inciting drug [28]. Another is that after radiotherapy permanent changes had been induced in stem cells' functional features, such as capacity of proliferation, consequently the reaction occurs when the stem cells are exposed to a triggering agent [29]. Nevertheless, Abadir and Liebmann [30] suggest that the stem cells cycle at a faster rate to maintain an adequate functioning on the irradiated zone, thus they are more susceptible to be damaged by active drugs. However, the absence of recurrence in cases that were rechallenged with the same drug, and reactions caused by noncytotoxic drugs do not support these hypotheses. Camidge and Price [19] reported that the role of idiosyncratic drug reactions should be emphasized more than the cytotoxicity of the drug due to the rarity of reaction, the speed of onset, and the extreme drug specificity. They

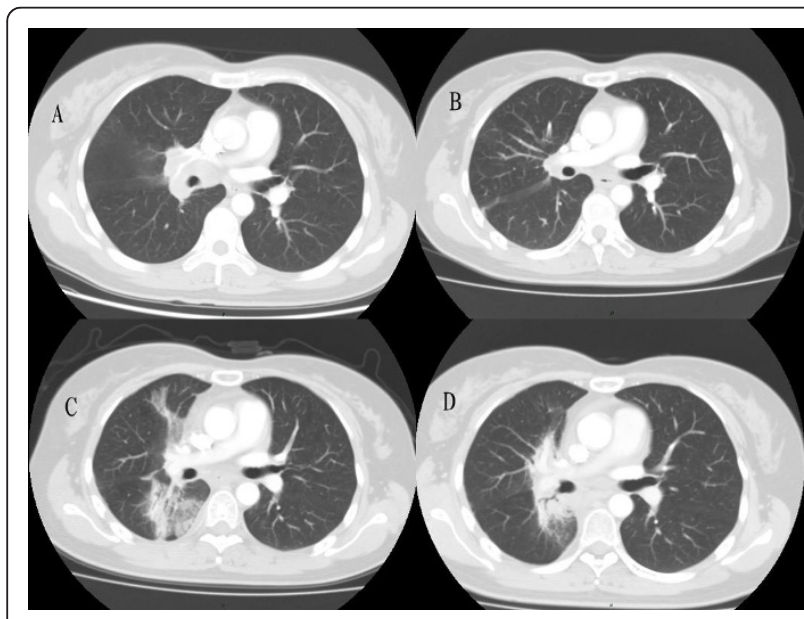

Figure 1 Thoracic CT scans of Patient 10 (A) before radiotherapy, (B) one month after end of radiotherapy, (C) 4 months after end of radiotherapy when RRP took place induced by consolidation chemotherapy, and (D) days after application of systematic steroids. (A)(B): No pulmonary infiltrate, (C): Pulmonary ground-glass opacity, (D): Partial resolution of the lung infiltrate

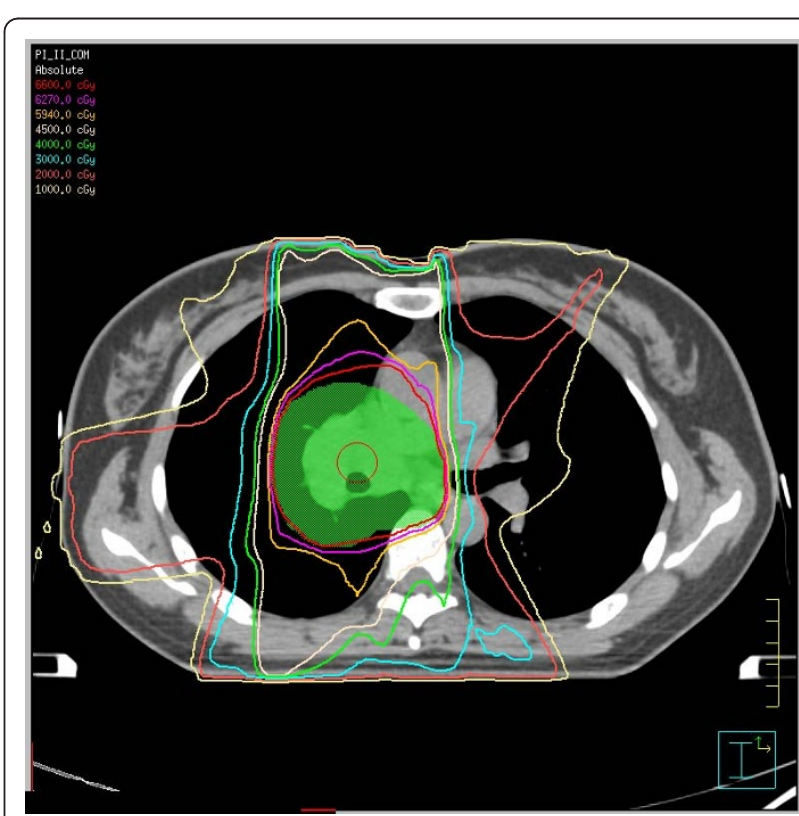

Figure 2 CT based IMRT plan of Patient 10 
also reported that radiation recall dermatitis may represent the koebner phenomenon [31]. No recurrence each time after rechallenge with the same drug supports the theory of drug hypersensitivity reaction. Further studies are needed to elucidate the etiology and pathogenesis of RRR.

\section{Conclusions}

Although RRP is a rarely reported phenomenon after previous thoracic radiotherapy, doctors should pay attention to this potential toxicity even after a long time interval from the previous radiotherapy or after several cycles of consolidation chemotherapy. Withdrawal of the causative agent and application of systematic steroids are the treatment of choice. Patients may be rechallenged safely with the same agent with steroid cover and careful observation, which needs more data to verify.

\section{Acknowledgements}

Thank Dr. Nan Bi for revising the manuscript.

\section{Author details}

${ }^{1}$ Department of Radiation Oncology, Cancer Institute (Hospital), Chinese Academy of Medical Sciences and Peking Union Medical College, Beijing, PR China. ${ }^{2}$ Department of Medical Oncology, Cancer Institute (Hospital), Chinese Academy of Medical Sciences and Peking Union Medical College, Beijing, PR China. ${ }^{3}$ Department of Radiation Oncology, Zhong Shan Hospital, Fudan University, Shanghai, PR China.

\section{Authors' contributions}

$J L$ and $X Z$ participated in the design and coordination of the study, and helped to analyze the data. LW, XD, and WJ conceived of the study, and participated in its design and coordination, and helped to analyze the data and draft the manuscript. All authors read and approved the final manuscript.

\section{Competing interests}

The authors declare that they have no competing interests.

Received: 30 November 2010 Accepted: 6 March 2011

Published: 6 March 2011

\section{References}

1. Azria D, Magné N, Zouhair A, Castadot $P$, Culine $S$, Ychou M, Stupp R, Van Houtte $P$, Dubois JB, Ozsahin M: Radiation recall: a well recognized but neglected phenomenon. Cancer Treat Rev 2005, 31:555-570.

2. Extermann $M$, Vogt $N$, Forni $M$, Dayer $P$ : Radiation recall in a patient with breast cancer treated for tuberculosis. Eur J Clin Pharmacol 1995, 48:77-78.

3. Garza LA, Yoo EK, Junkins-hopkins JM, VanVoorhees AS: Photo recall effect in association with cefazolin. Cutis 2004, 73:79-85.

4. Parry BR: Radiation recall induced by tamoxifen. Lancet 1992, 340:49.

5. Singer EA, Warren RD, Pennanen MF, Collins BT, Hayes DF: Tamoxifeninduced radiation recall dermatitis. Breast J 2004, 10:170-171.

6. Abadir $\mathrm{R}$, Liebmann J: Radiation reaction recall following simvastatin therapy: a new observation. Clin Oncol 1995, 7:325-326.

7. Camidge $R$, Price $A$ : Characterizing the phenomenon of radiation recall dermatitis. Radiother Oncol 2001, 59:237-245.

8. Schweitzer VG, Juillard GJ, Bajada CL, Parker RG: Radiation recall dermatitis and pneumonitis in a patient treated with paclitaxel. Cancer 1995, 76:1069-1072

9. Jeter MD, Pasi AJ, Brooks S, Burstein HJ, Wen P, Fuchs CS, Loeffler JS, Devlin PM, Salgia R: Gemcitabine-induced radiation recall. Int J Radiat Oncol Biol Phys 2002, 53:394-400.
10. Showel J, Hoover SV, Deutsch S: Radiation-recall. Int J Radiat Oncol Biol Phys 1993, 25:929.

11. Stein RS: Radiation-recall enteritis after actinomycin-D and adriamycin therapy. South Med J 1978, 71:960-961.

12. Kundak I, Oztop I, Soyturk M, Ozcan MA, Yilmaz U, Meydan N, Gorken IB, Kupelioglu A, Alakavuklar M: Paclitaxel-carboplatin induced radiation recall colitis. Tumori 2004, 90:256-258.

13. Friedlander PA, Bansal R, Schwartz L, Wagman R, Posner J, Kemeny N: Gemcitabine-related radiation recall preferentially involves internal tissue and organs. Cancer 2004, 100:1793-1799.

14. Ganem G, Solal-Celigny P, Joffroy A, Tassy D, Delpon A, Dupuis O: Radiation myositis: the possible role of gemcitabine. Ann Oncol 2000, 11:1615-1616.

15. Wallenborn PA, Postma DS: Radiation recall supraglottitis. A hazard in head and neck chemotherapy. Arch Otolaryngol 1984, 110:614-617.

16. Wiatrak BJ, Myer CM: Radiation recall supraglottitis in a child. Am J Otolaryngo 1991, 12:227-229.

17. Choi YW, Munden RF, Erasmus JJ, Park KJ, Chung WK, Jeon SC, Park CK: Effects of radiation therapy on the lung: Radiologic appearances and differential diagnosis. Radiographics 2004, 24:985-998.

18. Ma LD, Taylor GA, Wharam MD, Wiley JM: "Recall" pneumonitis: adriamycin potentiation of radiation pneumonitis in two children. Radiology 1993, 187:465-467.

19. MCLnerney DP, Bullimore J: Reactivation of radiation pneumonitis by adriamycin. Br J Radiol 1977, 50:224-227.

20. Hill $A B$, Tattersall SF: Recall of radiation pneumonitis after intrapleural administration of doxorubicin. Med J Aust 1983, 1:39-40.

21. Schwarte S, Wagner K, Karstens JH, Bremer M: Radiation recall pneumonitis induced by gemcitabine. Strahlenther Onkol 2007, 183:215-217

22. Castellano D, Hitt R, Ciruelos E, Cortés-Funes H, Colomer R: Biweekly vinorelbine and gemcitabine: a phase I dose-finding study in patients with advanced solid tumors. Ann Oncol 2003, 14:783-787.

23. Togashi $Y$, Masago K, Mishima M, Fukudo M, Inui K: A case of radiation recall pneumonitis induced by erlotinib, which can be related to high plasma concentration. J Thorac Oncol 2010, 5:924-925.

24. Chan RT, Au GK, Ho JW, Chu KW: Radiation recall with oxaliplatin: report of a case and a review of the literature. Clin Oncol 2001, 13:55-57.

25. Raghavan $\mathrm{VT}$, Bloomer WD, Merkel DE: Taxol and radiation recall dermatitis. Lancet 1993, 341:1354.

26. Burdon J, Bell R, Sullivan J, Henderson M: Adriamycin-induced recall phenomenon 15 years after radiotherapy. Jama 1978, 239:931.

27. Kellie SJ, Plowman PN, Malpas JS: Radiation recall and radiosensitization with alkylating agents. Lancet 1987, 1:1149-1150.

28. Bostrom A, Sjolin-Forsberg G, Wilking N, Bergh J: Radiation recall - another call with tamoxifen. Acta Oncol 1999, 38:955-959.

29. Seymour CB, Mothersill C, Alper T: High yields of lethal mutations in somatic mammalian cells that survive ionizing radiation. Int J Radiat Biol Relat Stud Phys Chem Med 1986, 50:167-179.

30. Abadir R, Liebmann J: Radiation reaction recall following simvastatin therapy: a new observation. Clin Oncol (R Coll Radiol) 1995, 7:325-326.

31. Camidge $R$, Price $A$ : Radiation recall dermatitis may represent the koebner phenomenon. J Clin Oncol 2002, 20:4130.

doi:10.1186/1748-717X-6-24

Cite this article as: Ding et al:: Radiation recall pneumonitis induced by chemotherapy after thoracic radiotherapy for lung cancer. Radiation Oncology 2011 6:24. 